\title{
Een mond vol tanden. Enkele gedachten over de zin van casuïstische criminologie
}

W.J.M. de Haan ${ }^{*}$

\section{Inleiding}

In de nacht van 13 september 1997 ontstaat in het centrum van Leeuwarden een vechtpartij tussen twee groepen jonge mannen. Hierbij komt de dertigjarige Meindert Tjoelker om het leven. Het voorval wordt als een geval van uitgaansgeweld beschouwd en geplaatst in een reeks van soortgelijke geweldsincidenten met dodelijk afloop. De dood van Tjoelker wordt als extra dramatisch ervaren omdat hij de volgende dag in het huwelijk zou treden. De dood van Tjoelker wordt als paradigmatisch beschouwd voor wat vanaf dat moment 'zinloos geweld' is gaan heten.

In de daarop volgende jaren is in de samenleving een brede maatschappelijke discussie op gang gekomen over de oorzaken en achtergronden van 'zinloos geweld'. En geweldsincidenten met dodelijke afloop die in brede lagen van de bevolking als zinloos worden ervaren, kunnen nog steeds aanleiding geven tot protestacties en stille tochten tegen 'zinloos geweld'. Het gaat dan om geweld waarbij de aanleiding futiel en de reactie excessief is en het slachtoffer en/of getuigen achteraf niet begrijpen wat de dader heeft bewogen. In het strafproces tegen drie van de vier verdachten in de zaak van Meindert Tjoelker bleek het moeilijk vast te stellen wat er die avond feitelijk gebeurd is. Het slachtoffer zou bezwaar hebben gemaakt tegen de vernielingen die door een van de mannen uit de andere groep werden aangericht. Maar getuigen blijken terzake tegenstrijdige verklaringen te geven en het forensisch onderzoek geeft geen uitsluitsel over wie vervolgens precies wat heeft gedaan. Waarom het tot de vechtpartij kwam is na het proces nog even onduidelijk als daarvoor. Op de zitting ben ik over de motieven van de daders niet veel wijzer geworden omdat de rechter hen bij die gelegenheid nauwelijks naar hun beweegredenen heeft gevraagd. Met zijn verzuchting

* Willem de Haan is hoogleraar Criminologie aan de Rijksuniversiteit Groningen. 
dat de drie verdachten zo 'opvallend onopvallend' zijn, gaf de rechter slechts te kennen dat de levensloop van de drie verdachten die geen van allen strafblad hadden, geen aanknopingspunten boden voor een verklaring van wat er die nacht in Leeuwarden is gebeurd.

Korte tijd later heeft Peter de W. (28) als de oudste van de drie in een televisie-interview echter de volgende tekst en uitleg gegeven:

"We waren een avond op stap, we gaan nooit op stap, echt een avond vol lol en plezier ... mijn zwager springt over een fiets ... valt onderuit en we hebben daar nog hartelijk om gelachen. Daarna zijn we de bocht omgegaan en heeft hij, mijn zwager, een beetje uit chagrijnigheid omdat we hem uitgelachen hebben denk ik, die fiets gepakt en op de weg gegooid en toen kwam er aan de overkant... begon er een scheldpartij tegen ons. Het ene lokte het andere uit en toen zijn we dat terug gaan doen, we zijn terug gaan schelden. Tot we op een gegeven moment van die andere kant hoorden 'most hier komme, dan sla ik die voor de bek.' Dat was voor ons de aanleiding om ernaar toe te gaan. Er is niet overlegd van: 'we gaan ernaar toe en we slaan ze in elkaar', helemaal niet. Dat we ernaar toe gegaan zijn, ten eerste was hardstikke fout, hadden we nooit moeten doen ... maar we zijn er wel naar toe gegaan, de confrontatie was er gekomen. Het is niet alleen - het is heel moeilijk te zeggen - niet alleen dat wij uit waren op een confrontatie, zij waren ook, door hun gedrag, uit op een confrontatie."

De dader probeert duidelijk te maken dat 'zinloos geweld' in dit geval een (onbedoeld) gevolg was van een reeks van gebeurtenissen waarin dader(s) en slachtoffer(s) op elkaar reageerden. Zoals zo vaak is achteraf moeilijk vast te stellen wie er is begonnen en waarom de woordenwisseling is uitgelopen op geweld. Zeker is alleen dat de dodelijke afloop door niemand is gewild of was voorzien.

\section{'Zinloos geweld'?}

Zulke openlijke geweldpleging als 'zinloos' te bestempelen verhult meer dan het verheldert . Het is de taak van de onderzoeker om na te gaan wat geweldplegers motiveert en wat er precies in en met het geweld wordt 'gezegd' (Blok 1991, 203). In de maatschappelijke discussie over 'publiek geweld' (Schuyt 1999) is echter sprake van een proces van 'dramatisering van het kwaad' (Tannenbaum 1938). Iedere vorm van openlijke geweldpleging tegen 
onbekenden wordt bij voorbaat als irrationeel beschouwd en plegers van publiek geweld worden collectief gedemoniseerd. Iemand die een ander 'zomaar' in elkaar slaat, zal door buitenstaanders al gauw als een verderfelijk type of een gevaarlijke gek worden beschouwd. Het is echter moeilijk zo niet onmogelijk om menselijk gedrag te begrijpen als dat al bij voorbaat moreel wordt veroordeeld (Baumeister 1997). Naarmate openlijke geweldpleging meer als willekeurig en ongemotiveerd wordt beschouwd, nemen gevoelens van onveiligheid alleen maar toe en wordt de tendens tot uitstoting van geweldplegers des te sterker (Schuyt 1995, 927). Om echter te zien welke aangrijpingspunten er zijn voor de bestrijding en voorkoming van dit soort geweld op straat, is aandacht voor de betekenis van geweld voor de verschillende betrokkenen vereist. Om het gebeurde te begrijpen, is het noodzakelijk om ook te horen wat de daders zèlf daarover te zeggen hebben. Om te kunnen begrijpen en verklaren waarom het onder omstandigheden tot openlijke geweldpleging tegen volslagen onbekenden kan komen, ligt het voor de hand dat de redengevingen van geweldplegers achteraf worden onderzocht (Schuyt 1993).

In de praktijk wordt forensisch-psychologen en psychiaters gevraagd het 'zinloze geweld' te verklaren uit specifieke kenmerken van de persoon van de dader en de omstandigheden waaronder het delict is gepleegd. Maar omdat uitdrukkelijk Pro Justitia wordt gerapporteerd, staat daarbij de vraag centraal of de individuele verdachte psychische stoornissen heeft en of eventueel in welke mate - de verdachte zijn misdrijf redelijkerwijs kan worden toegerekend. Het gaat dus om vaststelling van de mate van handelingsvrijheid en toerekeningsvatbaarheid (Mooij 2004). De criminologie houdt zich doorgaans niet bezig met verklaring van unieke, individuele gevallen. Het gevolg is dat telkens wanneer de samenleving met een zeer ernstig en schokkend geweldsmisdrijf wordt geconfronteerd, criminologen met een mond vol tanden staan. Kennelijk achten zij zich niet in staat om ook in uitzonderlijke gevallen verhelderende inzichten te geven in de condities en processen die individuen ertoe brengen zeer ernstig delicten te plegen. Omdat ik deze 'trained incapacity' onbevredigend vind, wil ik in deze bijdrage nagaan wat de mogelijkheden zijn voor een meer systematische toepassing van casuïstiek in de criminologie. Mijn stelling is dat criminologen zich niet moeten beperken tot verklaringen van criminele gebeurtenissen en gros, maar ook bereid en in staat zouden moeten zijn om en detail analyses van individuele casus te maken, althans van misdrijven gepleegd door 'normale' personen die niet psychisch gestoord zijn en als volledig toereke- 
ningsvatbaar kunnen worden beschouwd. Casuistische criminologiebeoefening is niet alleen van belang om een bijdrage te kunnen leveren aan een rationele maatschappelijke discussie over misdaad en straf, maar ook om de mens van vlees en bloed terug te brengen in de criminologie. Dit laatste is nodig omdat het mensbeeld in de hedendaagse mainstream criminologie sterk is verschraald. Veel criminologisch onderzoek gaat niet over mensen met concrete belevingen en belevenissen en met persoonlijke geschiedenissen en toekomstidealen, maar over processen, risicofactoren en variabelen. De mens is dan slechts een knooppunt van variabelen die op grootschalige manieren worden gemeten. Verondersteld wordt, dat crimineel gedrag uit de gevonden samenhangen tussen verschillende variabelen kan worden verklaard. Volgens Schuyt (2002) die in een discussiebijdrage in het sociologisch tijdschrift Mens en Maatschappij op dit probleem heeft gewezen, is dit een ernstige misvatting omdat we na het vaststellen van correlaties en verbanden vaak nog helemaal niets begrijpen en het verklarende werk nog moet beginnen (86). Nergens is de urgentie van dit inzicht nadrukkelijker aanwezig dan bij onderzoek naar oorzaken en achtergronden van 'zinloos geweld.'

\section{Sociologische criminologie}

Gangbare sociologisch-criminologische theorieën gaan vrijwel uitsluitend over oorzaken en achtergronden van geweld. Zij leveren nauwelijks iets nieuws op en doen bovendien geen recht aan het feit dat geweld een dynamisch proces en een bij uitstek zinnelijke beleving is. In plaats van de vraag waarom het tot geweldpleging is gekomen en wat geweldplegers heeft bewogen of bezield, gaat het steeds maar weer over de vraag wat de oorzaken zijn van geweld. Daarbij wordt tevergeefs geprobeerd een verschijnsel te verklaren dat men eigenlijk niet begrijpt. In de terminologie van Max Weber zijn zulke verklaringen niet 'sinnhaft adequat' en het is zelfs maar de vraag of theorieën die op deze manier worden ontwikkeld 'kausaal adequat' kunnen zijn. Het zou mooi zijn als we zouden kunnen komen tot een 'erklärendes Verstehen': een begrijpen en verklaren van geweld (Schinkel 2004, 15). Zolang het geweld zelf niet worden onderzocht, en we blijven steken in statistisch significante maar onbegrijpelijke en onduidelijke verbanden tussen op alle mogelijke manieren geoperationaliseerde individuele, sociale, economische, culturele en algemeen maatschappelijke factoren, staan we als het er op aankomt met een mond vol tanden. Een sociologie die geweldpleging werkelijk wil begrijpen en verklaren zal om te beginnen een beschrij- 
ving moeten geven van de fenomenologie, d.w.z. de verschijningsvormen en modaliteiten van geweld (Von Trotha 1997, 20). Met andere woorden, sociologen en criminologen zouden zich veeleer moeten afvragen wát er precies gebeurd is, alvorens zich te storten op de vraag waarom.

In zijn veelbesproken studie Seductions of Crime had Katz (1988) trouwens al eerder de stelling verdedigd dat criminologische theorievorming moet beginnen met het onderzoeken van de voorgrond van criminaliteit. Met de voorgrond bedoelde hij de inhoudelijke aspecten van crimineel gedrag, d.w.z. wat er precies gebeurt wanneer een bepaald (geweld)misdrijf wordt gepleegd en wat het plegen ervan voor de dader betekent en hoe hij het aan den lijve ervaart. Pas nadat deze voorgrond van crimineel gedrag is onderzocht, heeft het volgens Katz zin om andere relevante achtergrondfactoren zoals gender, race en class te onderzoeken en pas dan ook is er een reële kans dat nieuwe verbanden tussen achtergrondfactoren en voorgrondkenmerken worden gevonden. Het expla-nandum zou dan een 'narrative of action' moeten zijn, een beschrijving en interpretatie van de interactie tussen handelende individuen en een analyse van de patronen in het handelen van bepaalde typen actoren in bepaalde typen situaties waarin zij bepaalde doeleinden nastreven terwijl hun handelen aan bepaalde mogelijkheden en beperkingen is onderworpen.

\section{Motieven}

Wanneer we een antwoord zoeken op de vraag wat een pleger van 'zinloos geweld' bezielt en wat zijn motief is voor het plegen van 'zinloos geweld', worden we geconfronteerd met het feit dat sociaal-wetenschappelijke theorieën over motieven weinig ontwikkeld zijn. Doorgaans wordt aangenomen dat motieven drijfveren zijn die mensen tot handelen bewegen. Maar wat die drijfveren precies inhouden, welke verklaringskracht zij bezitten en in hoeverre geweld daarmee kan worden verklaard, daarover verschillen filosofen, psychologen en sociologen sterk van mening. Zo beschouwen sommigen handelingsmotieven als diepere wensen en verborgen verlangens waarvan actoren zich niet of nauwelijks bewust zijn, terwijl anderen motieven zien als redenen die actoren zelf bewust aanvoeren als verklaring voor hun gedrag. De socioloog Mills (1940) zag motieven niet als verwijzing naar innerlijke drijfveren van individuen, maar als verklaringen die actoren achteraf geven voor hun handelen (soms ook als rechtvaardiging of excuus). Bij het motiveren van hun handelen grijpen actoren als vanzelfsprekend terug op verkla- 
ringen die cultureel beschikbaar zijn in de vorm van een 'motievenvocabulaire' (Mills, 1940). Zulke redengevingen zijn gebonden aan specifieke situaties en moeten in die morele (rechtvaardigings)context worden gezien. De voortdurende discussies en fundamentele meningsverschillen over het begrip motivatie hebben ertoe geleid dat het motief van de actor als een problematische notie wordt beschouwd, waaraan de meeste sociologen en psychologen hun vingers liever niet branden. Om die reden is het motief ook wel smalend aangeduid als 'the joker in the psychologists pack' (Heller, 1979). Ook in de criminologie worden motieven van delictplegers meer verondersteld dan empirisch onderzocht. Het motief van de dader is een 'black box' waarin zich - in de woorden van Jacobs en Wright (1999) 'criminology's dirty little secret' bevindt. Een poging om die 'black box' in te vullen is het rationele-keuzeperspectief (Cornish en Clarke 1986).

\section{Rationele keuze}

In het rationele-keuzeperspectief wordt crimineel gedrag verklaard als uitkomst van keuzegedrag. Het door de dader veronderstelde verschil tussen de eventuele kosten en baten van zijn handelen is wat hem motiveert, zelfs als het gaat om schijnbaar irrationele vormen van crimineel gedrag (Clarke en Cornish, 1985). Ook 'zinloos geweld' zou kunnen worden verklaard als de uitkomst van een rationele afweging. We moeten ons dan voorstellen dat geweldplegers in fracties van seconden ingewikkelde en afgewogen beslissingen nemen door middel van een 'algebraïsch proces' dat zo snel werkt dat men zich er niet eens van bewust is. Zonder dat de geweldpleger het zelf in de gaten heeft, zouden de netto-opbrengsten van alle mogelijke reacties razendsnel doorgerekend en de voordeligste combinaties geselecteerd worden (Megargee, 1982).

Ik behoor tot hen die het niet erg verhelderend vinden om geweldpleging als uitkomst van een rationele keuze te beschouwen, vooral omdat daarmee te gemakkelijk voorbij wordt gegaan aan emotionele en morele aspecten van geweld.

\section{Impulsiviteit}

Uit empirisch onderzoek blijkt dat geweldplegers doorgaans impulsief reageren waarbij geweld vaak 'en passant' wordt gepleegd en het soms niet eens de bedoeling was om met een ander op de vuist te gaan, maar het 'gewoon' is gebeurd. Geweldplegers blijken over het algemeen veel temperament en weinig zelfbeheersing te hebben, bij het minste of geringste razend te worden en dan furieus tegen de vermeende opponent tekeer te gaan, 
zonder ook maar een ogenblik stil te staan bij de eventuele gevolgen van hun gewelddadig gedrag (Berkowitz, 1986). Soms hebben de (overbeheerste) daders achteraf ook 'geen flauw idee' hoe zij bij openlijke geweldpleging betrokken raakten en hoe het zover kon komen dat zij zodanig ernstig geweld hebben gebruikt dat zij anderen ernstig letsel hebben toegebracht. Zulke 'zinloze' gedragingen lijken er door toepassing van het perspectief van een (razendsnelle en onbewuste) rationele keuze niet echt begrijpelijker op te worden. Door uit te gaan van een rationele keuze benadering wordt de rationaliteit van impulsief gedrag sterk overschat, terwijl de emotionaliteit en expressiviteit van ervan sterk worden onderschat (Scheff, 1992).

In de mainstream criminologie is echter weinig belangstelling voor de emotionele en expressieve aspecten van (crimineel) gedrag, terwijl juist deze aspecten voor het verklaren van verschijnselen als 'zinloos geweld' van belang lijken zijn (De Haan en Loader, 2002).

\section{Morele emoties}

Vanzelfsprekend zijn er uitzonderingen. Zo heeft Matza (1964) bijvoorbeeld gewezen op de betekenis van emoties als verklaring voor gewelddadig gedrag. Om tot geweld over te kunnen gaan zouden de angst- en schuldgevoelens van de dader geneutraliseerd moeten worden en zou zijn wil tot handelen een sterke impuls moeten krijgen, bijvoorbeeld door een hevige emotie. Matza stelde dat het vaak morele emoties zijn die een zo sterke impuls geven dat daders overgaan tot het gebruik van fysiek geweld.

Meer recentelijk heeft Scheff (1992) onderzoek gedaan naar de samenhang tussen emoties en fysiek geweld. Hij ziet openlijke geweldpleging als een manier om pijnlijke gevoelens van tekortschieten te compenseren en meent dat een combinatie van onderdrukte woede en schaamte een emotionele kettingreactie op gang kan brengen waarbij uitbarstingen van woede en razernij vrijwel zeker uitlopen op impulsief, explosief geweld. Op basis van dit inzicht heeft hij een theorie ontwikkeld waarin achting en respect centraal staan. Geweld is volgens deze theorie een reactie op het teleurstellen van verwachtingen ten aanzien van het betoon van achting en respect voor de identiteit van de persoon. Wanneer iemand zich schaamt omdat hij voor zijn gevoel te kijk is gezet of belachelijk is gemaakt, zal hij geneigd zijn om op zo'n vernedering te reageren met geweld.

\section{Morele rechtvaardigingen}

Vaak staan mensen op het moment zelf niet of nauwelijks stil bij de drijfveren voor hun handelen. Bij onbezonnen, impulsief ('ontladings')geweld lijkt 
dit haast per definitie het geval. Geweldplegers kunnen dan pas achteraf stil staan bij de vraag waarom zij geweld hebben gebruikt. Mensen kunnen dan redenen voor hun handelen bedenken waaraan zij op het moment zelf niet hebben gedacht, maar die achteraf voor hen (en mogelijk ook voor anderen) een voldoende verklaring (motivering) geven voor hun gedrag. In veel gevallen zal die verklaring tevens een verontschuldiging zijn of een rechtvaardiging achteraf voor wat eerder is misdaan. Door na te gaan hoe de toedracht bij het geweldsincident wordt verteld (het narratieve aspect), wat de aanleiding en het verloop van het incident is geweest (het interactieve aspect), hoe het betekenis krijgt (het interpretatieve aspect), hoe het is beleefd (het affectieve aspect) en hoe erop wordt teruggezien (het reflexieve aspect), is het echter mogelijk te achterhalen wat de geweldpleger heeft bezield.

Verklaringen van daders kunnen aanwijzingen (clues) geven wat het plegen van een misdrijf voor hen betekende en hoe zij het aan den lijve hebben ervaren om crimineel te zijn. Uiteraard zijn altijd meer gedetailleerde duidingen mogelijk die de relatie tussen motivatie en gedrag verhelderen. Nog afgezien van de diepere inzichten die kunnen worden verkregen wanneer een in een therapeutische setting gedurende lange tijd regelmatig met een respondent kan worden gesproken. Overigens lijkt het verstandig om te blijven beseffen dat zelfs Freud na het lezen van een gevalsstudie van een moordenaar opmerkte dat we nu alles weten behalve waarom de moord werkelijk was gepleegd (Wertham, 1941: 193, aangehaald in Redl \& Toch, 1979: 192).

\section{Pleidooi voor een psychosociale criminologie}

Om te achterhalen wat respondenten precies onder woorden proberen te brengen is een analyse vereist die zoveel mogelijk recht te doen aan alle facetten van de verhalen die respondenten vertellen. Wij gaan er van uit dat het mogelijk is redengevingen van daders zodanig te analyseren en te interpreteren in de context waarin ze worden gegeven, dat systematisch verband kan worden gelegd tussen hun handelen en hun - op het eerste gezicht vaak gebrekkige, onbeholpen en soms ook tegenstrijdige verklaringen (Hollway en Jefferson, 2000).

Gelet op het schier oneindige aantal mogelijke factoren waarmee intentioneel gedrag kan worden verklaard, is het idee van een algemeen causaal verklaringspatroon waarvan slechts de parameters behoeven te worden ingevuld om menselijk gedrag begrijpelijk en voorspelbaar te maken, uiterst 
onaannemelijk. We weten maar al te goed dat het gedrag van een Hamlet of Raskolnikov onmogelijk is uit te leggen aan iemand die niet vertrouwd is met of ongevoelig is voor de gecompliceerdheid van sociaal en emotioneel menselijke gedrag. Om duidelijk te maken hoe de ene gebeurtenis tot de andere heeft geleid, met soms alle fatale gevolgen van dien, dienen we veeleer te denken in termen van wat de filosofe Anscombe de 'causale geschiedenis' van menselijk handelen heeft genoemd (Scheer 2001, 412).

Het begrijpen en verklaren van het gedrag van een geweldpleger vereist een complexer concept van handelingsmotivatie dan bij sociologisch-criminologische verklaringen gebruikelijk is. Handelingsmotieven zijn sociale constructies die het menselijk handelen indirect bepalen doordat mensen zich er 'bewust' van zijn dat zulke motiveringen causaal hun 'wil tot handelen' sterken. In het geval van 'zinloos geweld' voelen daders een innerlijke drang om onder omstandigheden op een bepaalde manier te reageren en zich te buiten te gaan aan geweld omdat zij hebben geleerd bepaalde impulsen als onweerstaanbaar te (kunnen) beschouwen (Baumeister, 1997). Zij voelen dan een innerlijke drang om onder omstandigheden op een bepaalde manier te reageren (Jansz, 1996). Enerzijds is die innerlijke drang om onder omstandigheden op een bepaalde manier te reageren individueel bepaald. Anderzijds scheppen maatschappelijke omstandigheden ook systemen van min of meer duurzame en cultureel overdraagbare predisposities d.w.z. van neigingen tot bepaalde manieren van doen en laten. Zo'n systeem van predisposities kan worden gedefinieerd als habitus (Bourdieu, 1977). Het is een gevoel voor verhoudingen dat iemand in staat stelt de betekenis van een situatie ogenblikkelijk te begrijpen en bijna instinctief - 'zelfs in het heetst van de strijd' - daarop een passend antwoord te vinden. Als zodanig hebben de aangeleerde en geoefende gedragsrepertoires die in concrete situaties aanleiding geven tot het volgen van voorspelbare geweldsscenario's het karakter van een 'tweede natuur'.

Om zoveel mogelijk recht te doen aan alle genoemde facetten van handelingsmotivatie, is een analyse vereist van de narratieve, interactieve, interpretatieve, affectieve en reflexieve aspecten van redengevingen van geweldplegers. Een zorgvuldige interpretatie daarvan biedt de mogelijkheid om enerzijds recht te doen aan de psychische complexiteit van het individuele subject en anderzijds aan het door en door sociale karakter van de levensloop en de identiteit van de persoon (Goodey 2000). In een psychosociale benadering van 'normale' - niet-gestoorde - geweldpleging, zou de toegevoegde 
waarde kunnen liggen van een criminologische casuïstiek ten opzichte van de forensisch-psychologische of -psychiatrische diagnostiek van pathologisch geweld. In hoeverre een dergelijke benadering overtuigend is, hangt ervan af of de 'context of justification' hermeneutisch is of causaal (Scheer, 2001).

\section{Literatuur}

- Berkowitz, L. (1986) Some varieties of human aggression: criminal violence as coercion, rule-following, impression management and impulsive behavior. In: Anne Cambell, John J. Gibbs (red.), Violent Transactions. The limits of Personality. Oxford, Basil Blackwell, 87-103.

- Blok, A. (1991) Zinloos en zinvol geweld. In: H. Franke, N. Wilterdink, C. Brinkgreve (red.), Alledaags en ongewoon geweld. Groningen, Wolters-Noordhof, 1991, 189-207

- Bourdieu, P.F. (1977) Outline of a theory of practice. Cambridge: Cambridge University Press.

- Baumeister, R. F. (1997) Evil. Inside Human Violence and Cruelty. New York, W.H. Freeman and Co.

- Clarke, R., D. Cornish (1985) Modeling offenders' decisions: a framework for research and policy. In: T. Michael, N. Morris (red.), Crime and Justice. An Annual Review of Research, Vol. 6. Chicago, The University of Chicago Press, 147-185.

- Cornish, D., R. Clarke (1986) The reasoning criminal: rational choice perspectives on offending. New York, Springer.

- Goodey, J. (2000) Biographical lessons for criminology. Theoretical Criminology 4, 2000, 4, 473-498.

- Haan, W. de, Loader, I. (2002) On the emotions of crime, punishment and social control. In: Haan, W. de, Loader, I. (eds.) Special issue: Crime, punishment and the emotions. Theoretical Criminology 6, 3. 243-254.

- Heller, A. (1979) A theory of feelings. Assen, Van Gorcum.

- Hollway, W. and Jefferson, T. (2000) Doing qualitative research differently. Free association, narrative and the interview method. London, Sage

- Jacobs, B.A. en Wright, R. (1999) Stick-Up, Street Culture, and Offender Motivation, Criminology 37, 149-173. 
- Jansz, J. (1996) Constructed motives, Theory and Psychology, 63, 3, 471484.

- Katz, J. (1999) Seductions of crime. Moral and sensual attractions in doing evil. New York: Basic Books.

- Matza, D. (1964) Delinquency and drift, New York: John Wiley.

- Megargee, (1982) Psychological determinants and correlates of criminal violence. In: M. Wolfgang, N. Weiner (red.), Criminal Violence London, Sage, 1982, 81-170

- Mills, C.W. (1940) Situated actions and vocabularies of motive, American Sociological Review, 5, 904-913.

- Mooij, A. (2004) Toerekeningsvatbaarheid. Over handelingsvrijheid. Amsterdam. Boom.

- Scheer, R.K. (2001) Intentions, Motives, and Causation. Philosophy 76, 397-413.

- Schinkel, W. (2004) The Will to Violence. Theoretical Criminology 8, 1, 5-31.

- Schuyt, C.J.M. (1993) Jeugdcriminaliteit in groepsverband. Delikt en Delinkwent, 23, 499-510.

- Schuyt, C.J.M. (1995) De crimineel als vreemdeling, Delikt en Delinkwent, 25, 9, 927-930.

- Schuyt, C.J.M. (1999) Publiek geweld, Delikt en Delinkwent, 29, 5, 383388.

- Schuyt, C.J.M. (2002) Mensbeeld en methode. Hoe brengen we de ervaring terug in de sociologie? Mens en Maatschappij, 78, 3, 186-188.

- Scheff, T.J. (1992) Rationality and emotion. Hommage to Norbert Elias. In: J. Coleman, T. Fararo (red.), Rational choice theory: advocacy and critique. Newbury Park, Sage, 101-117.

- Tannenbaum, F. (1938) Crime and the Community, Boston, Ginn.

- Trotha, T. von (1997) Zur Soziologie der Gewalt. Kölner Zeitschrift für Soziologie und Sozialpsychologie 37, 9-56.

- Wertham, F. (1941) Dark legend. New York, Duell. Sloan and Pierce. 